\title{
Full-scale experimental and numerical study about structural behaviour of a thin-walled cold-formed steel building affected by ground settlements due to land subsidence
}

\author{
J. A. Ortiz, L. A. Hernández, M. Hernández, J. Pacheco, M. E. Zermeño, and R. Salinas
}

Autonomous University of Aguascalientes, Aguascalientes, México

Correspondence to: J. A. Ortiz (jose.ortiz.lozano@gmail.com)

Published: 12 November 2015

\begin{abstract}
Land subsidence due to ground water withdrawal is a problem in many places around the world (Poland, 1984). This causes differential ground settlements that affect masonry structures, because these structural materials do not exhibit an adequate performance beyond a certain level of angular distortion. This work presents the experimental and numerical results about a study regarding the performance of a full-scale thinwalled cold-formed steel building affected by ground differential settlements due to land subsidence. The experimental stage consisted in the construction of a test-building to be subjected to differential settlements in laboratory. The numerical stage consisted in performing a numerical non-linear static pull-down analysis simulating the differential ground settlements of the test-building. The results show that the structural performance of the tested building was very suitable in terms of ductility.
\end{abstract}

\section{Introduction}

Ground failure associated with land subsidence is the primary geotechnical hazard in several cities in central Mexico (Arroyo et al., 2004), that has caused enormous economic loss by damaging public and private properties, including dwellings. The damage caused by ground failures is variable and considerable, even though the local government is aware of this problem and has undertaken steps to mitigate ground failure-related damages. Active fracture zones associated with land subsidence induce displacements in buildings in the form of differential settlements, which cause damage to structural systems in dwellings, especially those based on masonry which is the principal construction method used in one or two-story dwellings,. The most common and visible damage occurs in walls which fails by shear force because of their low capacity to absorb angular distortion.

Cold-formed steel sections have instability problems because of the effects of certain buckling modes due to the slenderness of the section (Anapayan and Mahendran, 2012). One of the principal uses for this type of material is for structural frames in the form of modules, which are most commonly assembled using elements with edge-stiffened flanges and elements with simple flanges with different dimensions and gages. The majority of studies on cold-formed steel structures have been primarily focused on their performance under seismic events, e.g., the performance under lateral loads using non-linear static push-over analysis, as described in the specifications provided by the Applied Technology Center (ATC-40, 1996). However, few studies have focused on the case of cold-formed steel structures affected by ground settlement due to land subsidence phenomenon; therefore, conducting research on this issue is a priority for zones affected by land subsidence.

Because of its mechanical properties, the structural performance of thin-walled cold-formed steel structures could allow large displacements to be absorbed without failing. In this report, the results of an experimental and numerical study, with the objective of assessing the performance of a full-scale thin-walled cold-formed steel building under angular distortion and simulating the differential ground settlements due to land subsidence phenomenon, is presented. 


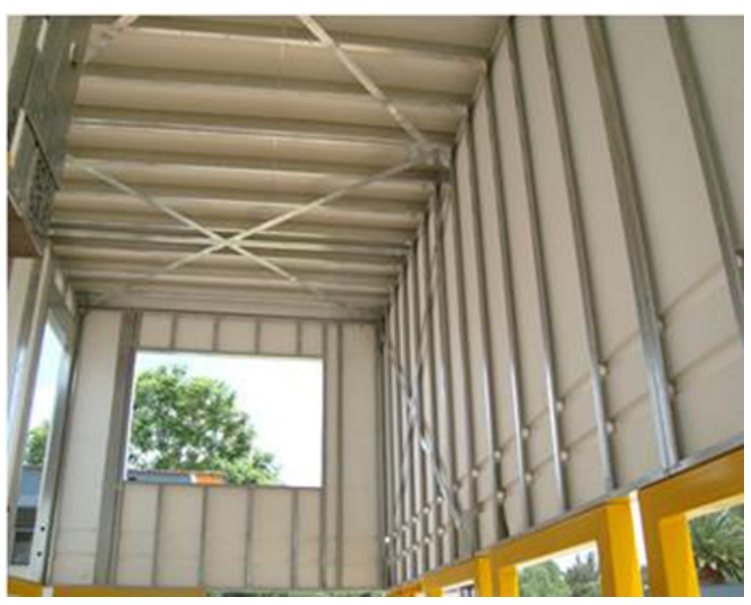

Figure 1. Interior view of the cold-formed steel structure.

This test building is a new construction system to be used in houses and the main objective is to know the structural performance for land subsidence.

\section{Experimental and numerical methodology}

\subsection{The test building subjected to vertical displacements}

A full scale thin-walled cold-formed steel one-story building with 8 bearing walls of $2.5 \mathrm{~m}$ high was built. Figure 1 shows interior view of the housing which was structured with simple channel section 350T125-33 elements (tracks) on the top and bottom parts of the frame and vertical stiffened channel section 350S162-33 elements (studs). The center to center distance between the studs was $400 \mathrm{~mm}$. Used as a sheathing material; a high-density expanded polystyrene panel with a thickness of $75 \mathrm{~mm}$ was inserted between the studs. The connections between the studs and the tracks were made using \#8 flat head self-drilling screws with a longitude of $20 \mathrm{~mm}$ and applied to each joint; thus, four screws were used. To fasten the wall frames to the ground, "hold-down" type anchors at a right angle, constructed of steel plate A-36 of 4-mm thickness, were put in each bottom end of the frame; the anchors fastened the frame using 14 self-drilling screws \#10 that were $38 \mathrm{~mm}$ in longitude, and a steel screw A-307 Gr. B with a diameter of $16 \mathrm{~mm}$ was used to anchor the frame to the ground. A double action hydraulic actuator with a $160 \mathrm{kN}$ capacity connected to the ground was necessary to apply the monotonic vertical pull-down load on the bottom end of the frame, which was gradually increased to reach a $140 \mathrm{~mm}$ target vertical displacement. Measuring instruments were placed on the points of interest to evaluate the displacements for a total of 20 points distributed uniformly on the area of each frame. The average rate of load application was $12.5 \mathrm{~mm} \mathrm{~min}^{-1}$.

Tests on lateral load in thin walled cold-formed steel wall frames were conducted to obtain information related to the mechanical performance of the wall in terms of the elastic rotational stiffness of the system to calibrate the parameters of the finite element models.

\subsection{Static non-linear pull-down analysis}

The methodology followed in this study consisted on performing a non-linear pull-down analysis to a full scale thinwalled cold-formed steel one-story building affected by vertical displacement and simulating the effects produced by land subsidence, which develops gradually in buildings over the years.

The pull-down analysis of a structure can be considered when one of its supports suffers a vertical displacement, generally downwards. The results for this type of analysis are similar to the results that occur when a static non-linear pushover is used; the only difference is the direction in which the displacements are evaluated. In the push-over analysis, the horizontal displacements are assessed; in the pull-down analysis, the focus is on the vertical displacements, which can be generated by different causes. An important parameter in this type of vertical displacement (settlement) is its rate, which depends on the landslide type or other phenomenon that affects the structure (Negelescu and Foerster, 2010). A calibration of the model analysed was conducted based on all of the variables of influence, such as the aspect ratio, the gauge of the studs and tracks, the distance between the studs, the thickness of the sheathing, the elastic rotational stiffness and the mechanical properties of the materials involved, e.g., the modulus of elasticity and shear modulus. Afterwards several numerical simulations were performed using finite element software (SAP 2000, 2008) to verify that the numerical structural behaviour was equal to that of the experimental tests. Subsequently, the numerical pull-down analysis was performed on the virtual structural model by applying a gradual vertical monotonic incremental vertical displacement on the support (control joint), which simulated a differential settlement of the ground due to the land subsidence phenomenon.

The angular distortion is the ratio between the displacement and the longitude of the analysed structural frame; neither the studs nor the wall frames supported any vertical or horizontal load. The behaviour of the virtual model was assessed by obtaining the values of the moment dependent on the angular distortion for each step in the application of incremental displacement beyond the linear regime and adopting the following methodology:

1. Building the virtual model of cold-formed steel without any type of sheathing in the non-linear analysis SAP 2000 (2008) software based on the geometry and number of elements (studs and tracks).

2. Assigning properties: mechanical parameters of the materials (steel and sheathing), geometrical properties of the cross-section of cold-formed steel elements, applied loads and states of the load. 


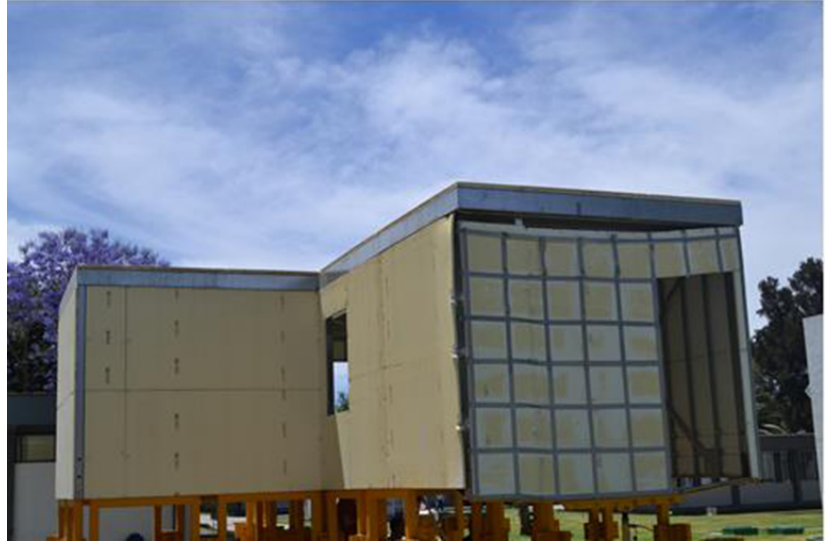

Figure 2. North Wall at the experimental test.

3. Calibrating the virtual model to reproduce the structural behaviour with lateral loads based on experimental tests conducted for the expanded polystyrene system, which are based on elastic rotational stiffness values, elasticity and shear modulus.

4. Assigning moment-rotation curves for distortional and local buckling on the ends of each stud to simulate plastic hinges (Ayhan and Schafer, 2002)

5. Configuring parameters for static non-linear pull-down analysis: maximum displacement, control joint and number of steps.

6. Running non-linear analysis on the virtual model and processing the results.

\section{Results and analysis}

\subsection{Experimental results}

The experimental phase of housing prototype was carried out in three stages vertical displacement applied in the central part of the rear wall located at the North end of the building. Figure 2 show the North wall during the experimental test. The cumulative total displacement was around $150 \mathrm{~mm}$. The affected area by the pull-down effect corresponds to the West, Central, East and North walls. Figure 3 shows the structure and the location of the North and Central walls. Elements with the most significant damage were the Central and North walls. In the first phase of displacement $(50 \mathrm{~mm})$ damage and deformations due local buckling in bottom tracks were observed. The more affected tracks at this stage correspond with those located in the north and central walls, that connect at the point of application of displacements. In the second phase of displacement $(100 \mathrm{~mm}$ accumulated), the polystyrene sheathing begins to detach from the metal structure without being broken. The diagonal bracing which at minimum vertical movements begin to bear and

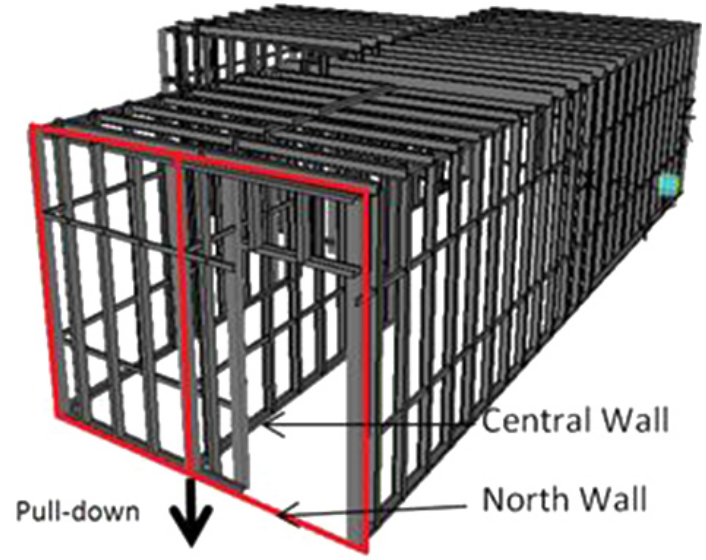

Figure 3. Structuring of housing and location of North and Central walls (SAP 2000, 2008).

transmit tensile and compression forces. At this stage bending stresses are greatly enhanced by generating excessive deformations in bottom tracks. This condition of stresses, coupled with the presence of stiffening elements such as studs and connecting plates, causes plastic hings mainly in those segments of walls that connect to the bearing wall (Fig. 4). At the final stage ( $150 \mathrm{~mm}$ accumulated) some structural elements reached their maximum allowable load. Bottom tracks start to break at vulnerables areas near to bolted connections. Polystyrene sheathing completely breaks in top and bottom ends of walls affected and most of the connectors between slab and walls completely fail.

\subsection{Numerical results}

The parameter used to evaluate the performance of studs in affected walls is the relative moment value $\left(M / M_{\mathrm{p}}\right)$, which measures the ability of the element to withstand bending moments in relation to the distortion applied in each of the walls. According with this was observed that in the case of the north wall, the stud 416 located at the point of application of displacement, distortion reached a value of 12 to $58 \%$ of its bending capacity. In the case of Central wall stud 528 reached $98 \%$ of capacity to a distortion value only $5 \%$. The stud 531 achieves $100 \%$ capacity for a distortion of about $7 \%$. The rest of the studs on each of the walls studied showed lower values than those listed in this paragraph. According to the numerical analysis we can see that the behavior of structural elements is excellent as it allows high levels of distortion, without elements reach fail.

\section{Conclusions}

The cold-formed steel structure with polystyrene sheathing presents a greater flexibility in comparison with other materials like OSB wood, calcium silicate, and gypsum because the 


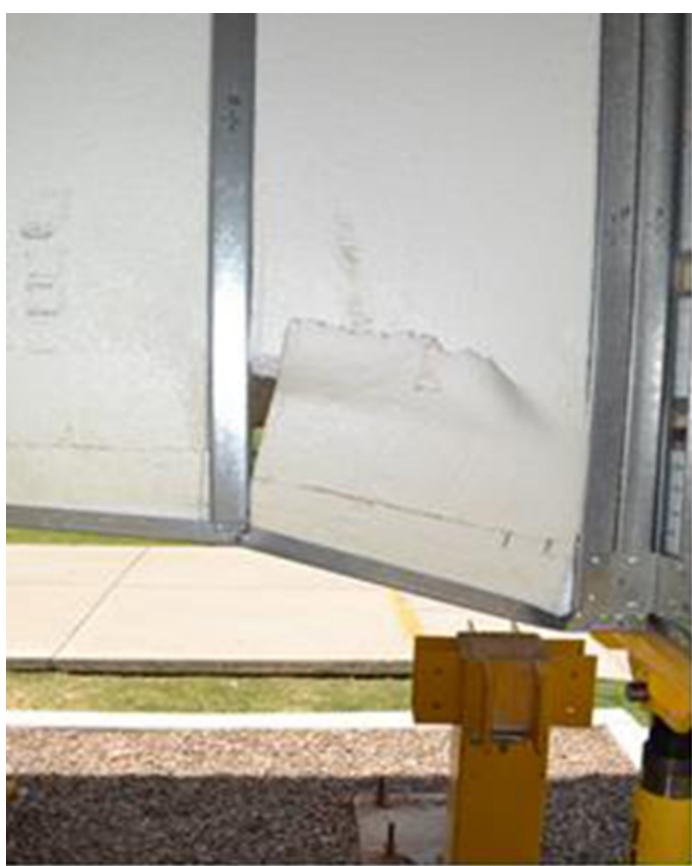

Figure 4. Excessive deformations in bottom track and fail of polystyrene.

polystyrene allows significant displacements (vertical settlement expressed as angular distortion) without suffering excessive damage; this result has been verified from a numerical standpoint by determining the relative moment. This construction system has an excellent behaviour when considering flexibility. Lastly, using structures based on cold-formed steel wall frames with polystyrene sheathing would be suitable to reduce damages and guarantee structural safety in housing structures constructed in zones affected by ground settlement due to land subsidence. Nowadays this construction system is adequate to apply it in one or two-story buildings. On the other hand, due its characteristics is possible to use with different materials in order to improve the structural performance.

\section{References}

Anapayan, T. and Mahendran, M.: Improved design rules for hollow flange sections subject to lateral distortional buckling, Thin Wall. Struct., 50, 128-140, 2012.

Arroyo, M. G., Zermeño, E., Castañeda, J. A.: El agrietamiento en Aguascalientes, causas y efectos, primera edición; Universidad Autónoma de Aguascalientes, Aguascalientes, 2004.

ATC-40: Seismic evaluation and retrofit of concrete buildings, Seismic Safety Commission, State of California, Sacramento, California, Developed by the Applied Technology Council, 1-316 (SSC Report no. 96-01), 1996.

Ayhan, D. and Schafer, B.: Moment-rotation characterization of cold-formed steel beams, Advancing Cold-Formed Steel Earthq Eng. (Research Report), 02, 1-33, 2002.

Negulescu, C. and Foerster, E.: Parametric studies and quantitative assessment of the vulnerability of a RC frame building exposed to differential settlements, Nat. Hazards Earth Syst. Sci., 10, 1781-1792, doi:10.5194/nhess-10-1781-2010, 2010.

Poland, J. F.: Guidebook to studies of land subsidence due to ground-water withdrawal, prepared for the International Hydrological Program, Working Group 8.4 UNESCO, 1-303, 1984.

SAP 2000: Structural Analysis Program Advanced version 12.0.0, Berkeley, Ca, Computers and Structures, Inc., 2008. 